\title{
SANTA vs. public tuberculosis hospitals: the patient experience in the Free State, 2001/2002
}

\author{
JC Heunis, PhD \\ Centre for Health Systems Research \& Development, University of the Free State \\ HCJ van Rensburg, DPhil \\ Centre for Health Systems Research \& Development, University of the Free State
}

H Meulemans, Ph.D

Department of Sociology, University of Antwerp

Correspondence address:

Dr JC Heunis

CHSR\&D (100)

University of the Free State

PO Box 339

Bloemfontein, 9300

Tel : (051) 401-2181

Fax : (051) 444-5011

E-mail : I leunisj.hum(a)mail.uovs.ac.za

\begin{abstract}
Curationis 30(1): 4-14
This paper reflects on the appropriateness of the decision to close down a nongovernmental organisation (NGO), state-aided tuberculosis (TB) hospital in the Free State in 2003. Henceforth hospitalisation of TB patients would take place at public district hospitals. A survey conducted late-2001/early-2002 revealed a more positive patient experience of hospitalisation for TB in public hospitals than in the NGO hospital. Consideration of the patient experience serves to inform the debate concerning continued outsourcing of TB hospital care to NGOs in South Africa. This study discusses comparative findings in respect of patients' biographic and socio-economic characteristics, health beliefs, satisfaction with hospitalisation, experience of stigmatisation, adherence to treatment and absconding from hospital.
\end{abstract}

\section{Opsomming}

Hierdie artikel reflekteer op die toepaslikheid van die besluit om ' $n$ nie-regerings organisasie (NRO), staat-ondersteunde tuberkulose (TB) hospital in 2003 te sluit. Voortaan sou die hospitalisasie van TB pasiënte in openbare distrikhospitale plaasvind. ' $n$ Opname wat laat-2001/vroeg-2002 uitgevoer is het " $n$ meer positiewe pasiëntervaring van hospitalisasie vir TB in publieke hospitale as in die NRO hospitaal openbaar. Oorweging van die pasiëntervaring dien om die debat rakende voortgesette uitkontraktering van TB hospitaalsorg aan NROs in Suid-Afrika toe te lig. Dié studie bespreek vergelykende bevindinge met betrekking tot pasiënte se biografiese en sosioekonomiese kenmerke, gesondheidopvattings, tevredenheid met hospitalisasie, ervaring van stigmatisasie, trouheid aan behandeling en "dros" uit die hospitaal.

Introduction

Excellence within any given hospital service may be described by means of standards and criteria in accordance with the expectations of the different roleplayers: funding bodies, service providers and patients. Among these patients are neglected in the South African "hospital" literature. This is contrary to an international tendency to assess the opinions of health service users as an integral part of quality evaluations (Schneider \& Palmer, 2002: 32). Also, the (social) experience of hospitalisation has not been systematically studied in any of the major hospital settings in South A frica, be they public, private-for-profit, industry-based, state-aided or voluntary. The dearth of such research can only mean that health policy makers and managers are neither supported by "social statistics" nor by understanding of the patient perspective to inform their decisions about hospitals. 
This study reflects on the patient experience at the one NGO hospital offering TB care in the Free State one year before its closure in January 2003. Ownership of this hospital vested with the South African National Tuberculosis Association (SANTA). This NGO has operated specialised TB hospitals across South Africa since the 1950s. In 1999, SANTA had 22 hospitals specialising in TB care: seven in the Eastern Cape, six in KwaZulu-Natal, three each in Gauteng and Mpumalanga, two in the Western Cape, and one in the Free State. By 2003, not only the Free State, but also North West, Northern Province and the Northern (ape, no longer had a SANTA hospital (Inpatient Care Team 2003). There was clearly a questioning of the traditional role of SANTA hospitals and a trend to oust this NGO provider from intramural TB care. In the Free State, at least, this role was largely assigned to public hospitals.

The Claudius Brink SANTA Centre (Santoord Hospital) was established in 1952 and was operated by SANTA until its closure in 2003. Santoord was a provincially-aided hospital (Van Vuuren 2001 ). The annual number of admissions was highest in 1997 at 710 patients. During 2001 the hospital admitted 602 patients (442 males, 152 females, and 8 children) of whom 477 were discharged, 11 transferred, 23 absconded, and 105 died. Santoord Hospital's budget for 2002/2003 was R7 632 756. The cost to the Free State Department of Health per patient day for this period was R 104-55. Santoord was not physically designed nor equipped to accommodate MIRTBB patients. However, it did so for three years after the closure of the private Allanridge Chest Hospital in 1999. Just before its closure the hospital accommodated 145 TB patients. Drugsusceptible patients were hospitalised for two to three months and multi-drug resistant TB (MDRTB) patients for seven to nine months. The mean length of stay at the hospital was 125 days. MDRTB patients at Santoord were treated in collaboration with doctors/specialists from the University of the Free State and were discharged once they had produced three consecutive negative sputa. After discharge they would return to the hospital on a two-monthly basis for follow-up examinations. Santoord closed at the same time nationally SANTA was facing allegations of financial impropricty at its head office, and unacceptable standards of care at some of its hospitals (Altenroxel, 2001: 6; Kirk, 2001: 3; Van Rensburg, 2000: 2).

The era of NGO hospitalisation for TB in the Free State has then seemingly come to an end. Barring those few patients who can afford private care and a small number of patients in the new provincial MDR-unit, TB patients are at present treated at primary health care (PHC) clinics and public hospitals. Except for MDRTB, this also means that the practice of long-term hospitalisation for TB has now been abandoned.

Despite its unique position as the Free State's only TB hospital, and even amidst an escalating $T B$ epidemic in the province, Santoord Hospital's closure was imminent. Reportedly, the patients addressed letters to the Free State MEC for Health complaining, amongst others, about food at the hospital and the staff who they (the patients) experienced as "dominating". All these dynamics pointed to the necessity to gain insight into how the patients themselves experienced Santoord Hospital. As it was clear that public district hospitals were already taking over the hospitalisation of TB patients previously referred to Santoord, it was thus also opportune to conduct a cross-sectional study to compare the TI3 hospital patient experience in these two types of hospitals.

The current study formed part of a larger project, the Joint research project on tuberculosis control in the Free State: from infection to cure. This project studied TB from various angles with the aim to inform the provincial TB programme and enhance the efficiency of $\mathrm{TB}$ control in the province (cf. Van Rensburg, Meulemans \& Rigouts, 2005: ii-iv; Van Rensburg, Meulemans, Rigouts, Heunis, Janse van Rensburg, Matebesi, Van der Spoel, Timmerman, De Graeve, Pauwels, Portaels, Grysecls \& Van Houtte, 2005: 1127). Two focal and complementary dimensions applied in the larger study, i.e. social aspects and health service aspects. The social dimension included, on the one hand, ТВ patients' needs, perceptions, experiences and circumstances, health-seeking behaviour, health service utilisation and satisfaction, coping strategies, support systems, and adherence to treatment (cf. Matebesi, Meulemans \& Timmerman, 2005: 154). On the other hand, the social dimension also involved a focus on $\mathrm{TB}$ programme managers and staff and their views, amongst others, on hospitalisation for TB (cf. Heunis, 2005: 221 ). This article discusses findings related to TB hospital patients' experience of hospitalisation for the discase (cf. also Heunis 2004a: $161-210$ ). The findings are inclusive of these patients' biographic and socio-economic characteristics, health beliefs, satisfaction with hospitalisation, experience of stigmatisation, adherence to treatment and absconding from hospital. In all this data helps to reflect on the research question: how appropriate was the closing of a hospital that contributed to TB control for half a century?

\section{Methods}

The imminent closure of Santoord Hospital meant that a cross-sectional study, i.e. a once-off survey of TB hospital patients at Santoord and the sampled public district hospital, would be an appropriate design. Similar to medical procedures like a biopsy or an $x$ ray, cross-sectional studies observe whatever is being studied as if a section of time is being cut out for observation (Baker, 1994: 106). No suitable instrument being in existence an interview schedule was developed from the literature. This schedule contained both closed and open-ended questions. The open-ended questions were included so that respondents in their answering of questions would make use of what came to their own - rather than the researchers' - minds. The instrument was pre-tested to determine its effectiveness and its problems and to improve its reliability. Preliminary informal pre-testing was followed by formal pre-testing under conditions similar to the actual survey. For purposes of the formal pre-test the schedule was administered in face-toface interviews with a sub-sample of patients at Santoord Hospital and the five district hospitals. During these interviews the interviewers wrote comments on the questionnaire and thereafter discussed these in an interactive context with the other interviewers and the first author. The questionnaire was corrected in respect of skipped items, response set patterns, and open-ended questions that solicited ambiguous answers. While it is a limitation of the study that the questions were not subjected to tests of validity, the schedule was used to interview 90 
TB hospital patients during October 2001 to March 2002.

In the case of Santoord Hospital respondents were selected from an upto-date list by means of a table of random numbers. Fifty-five Santoord patients were selected from the 175 hospitalised at the time. A hindrance experienced in sampling patients in the case of public hospitals, was that these hospitals were not reporting institutions in respect of $\mathrm{TB}$ and could not provide any kind of meaningful sampling framework to select respondents from. Consultations with the managers of the male and female wards in each of the hospitals showed that between six and ten confirmed adult ( 15 years and older) PTB cases were hospitalised at the time of the fieldwork. It was then decided to randomly select $50 \%$ of all such cases which realised a sample size of 35 public TB hospital patients. Six public district hospitals in the Free State participated in the research: one in Thaba Nchu (Dr. J.S. Moroka Hospital), two in QwaQwa (Elizabeth Ross and Mofumahadi Manapo Mopeli hospitals) and Goldfields (Goldfields, Odendaalsrus and Virginia hospitals). The selection of these hospitals was purposive and based on their serving the three high-burden TB areas in the province targeted by the larger Joint Free State TB Research Project. These sampling techniques and sample sizes resulted in a sample representative of NGO hospital TB patients, as well TB patients in public district hospitals in three high-burden areas in the Free State - Cf. also Heunis (2005: 221); Janse van Rensburg-Bonthuyzen (2005: 200); and Matebesi et al (2005: 158).

Three fieldworkers conducted the interviews in the patients' home language (mostly Sesotho). Editing of completed interview schedules took place on a daily basis in an interactive team context. This involved item-by-item checking of the completed schedules to ensure consistency, verify and improve the completeness and the clarity of the information recorded by the interviewers and, when necessary, return the following day to interviewees to obtain missing data and clarify ambiguous information.

In order to calculate differences in the satisfaction of patients with various aspects of hospitalisation the chi-square test was used. The type of hospital, NGO vs. public. was the independent variable.
Likert scale measurements of patients' beliefs about how they fell ill, agreement with the necessity of their hospitalisation, satisfaction with care, experience of stigmatisation, and views of the hospital staff represented the dependent variables. Assuming equal intervals between scores of the Lickert Scale, certain statistically significant differences $(p<0.05)$ are noted. Likert scales require a minimum of two categories (Neuman, 2000: 182). In this analysis the two outlying categories on either side of the Likert Scale were merged and the uncertain category eliminated, so that two categories remained, e.g. satisfied and dissatisfied. As it is suited to both nominal and ordinal measurements, lambda (ë) was the chosen measure of statistical association. Lambda is an asymmetric statistic measure of association with values ranging between 0.0 and 1.0 .

After consideration of the research protocol by the Ethics Committee ethical clearance for the Joint Free State TB Research Project and the current study was obtained from the Faculty of Health Sciences, University of the Free State. Authorisation and support for the research was also obtained from concerned managers of the Free State Department of Health; i.e. from the Head of Health, the Chief Executive Officer for Southern Free State Regional Complex, and the District Managers for Thaba Mofutsanyana and Lejweleputswa. Authorisation and support for the research was also obtained from the Provincial Manager of SANTA.

The following ethical principles were maintained in respect of the patient respondents:

- Informed consent:

Respondents were informed about the purpose the research project and their participation in the research was voluntary. Consent was sought by means of an explanatory letter in the case of literate respondents and reading of this letter to illiterate respondents.

- Confidentiality: The information supplied by respondents was treated as confidential.

- No harm to research subjects: Completion of interviews with ill and/or fatigued TB hospital patients was interrupted and postponed until such time they indicated they were fit to continue

Validation of the results of the current study took place via 14 presentations: six at district-level (Heunis, 2002b); two at provincial-level (Heunis, 2002a; Heunis \& Van Rensburg 2002); two at the local university (Heunis, 2002c; 2002d); one at a national conference (Heunis, 2003), and three at international seminars/ congresses (Heunis, 2002e; 2002f; 2004a). While the research feedback was primarily directed towards health managers and workers at the facility, district, provincial and national-levels, many of the research feedback sessions included NGO representatives, academics, policy-makers, and national and international collaborators. These sessions, and particularly the conference, A multidisciplinary approach to research, policy and practice, hosted at the University of the Free State (Bloemfontein - November, 11-12), were marked by genuine interchange between the health system research and practitioner communities.

\section{Findings}

\section{Patients' biographic and socio- economic characteristics}

The mean age of both the Santoord Hospital patients and the public hospital patients was 37 years. In the combined sample the youngest patient was 15 and the oldest 59. Amongst the 55 Santoord Hospital patients, $52(95 \%)$ and the 35 public hospital patients, $34(97 \%)$ were black. The remainder of patients in both cases were coloured.

At both the Santoord $(n=40 / 73 \%)$ and the public hospitals $(n=21 / 60 \%)$ males constituted large majorities. Given that the necessity for hospitalisation for $\mathrm{TB}$ is often the consequence of nonadherence to (ambulatory) TB treatment, the higher proportions of males undergoing intramural care suggests that their adherence was poorer than that of females. Skewed male representations in TB hospital patient numbers have also been reported in the USA (Singleton, Turner, Haskal, Etkind, Tricarico \& Nardell, 1997: 838).

In 1999, the adult literacy rate in South Africa was 85\% (Turner, 2002: 1449). Similarly, as judged by their ability to read a letter or a newspaper in their home 
Table 1: TB hospital patients' gender, race and functional literacy

\begin{tabular}{|l|l|l|l|}
\hline \multicolumn{2}{|c|}{ SH $^{\lrcorner}$} & PH $^{\mathrm{b}}$ \\
\hline Gender & Male & $40(72.2)^{\mathrm{c}}$ & $21(60.0)$ \\
& Female & $15(27.3)$ & $14(40.0)$ \\
\hline Race & Black & $52(94.5)$ & $34(97.1)$ \\
& Coloured & $3(5.5)$ & $1(2.9)$ \\
\hline Functional literacy & Yes & $49(89.1)$ & $32(91.4)$ \\
& No & $6(10.9)$ & $3(8.6)$ \\
\hline
\end{tabular}

a. Santoord Hospital

b. Public hospitals

c. $n(\%)$

language, respectively about one in every ten patients at both Santoord $(n=6 /$ $11 \%)$ and at public hospitals $(n=3 / 9 \%)$ were not functionally literate.

Prisoners very often originate from the most vulnerable sectors of society - the poor, the mentally ill and those dependent on alcohol or drugs. These groups already have an increased risk of diseases such as TB. In prison, these problems are amplified by poor living conditions and overcrowding (Kimerling, 2000): S161; Reichman \& Hopkins Tanne, 2002: 90$)$. One-third $(n=18 / 33 \%)$ of the Santoord Hospital patients had been in prison at least once, and had on average endured 25 months of incarceration. Among the public hospital patients onequarter ( $n=9 / 26 \%)$ had been in prison, on average for 16 months. That so many of the hospitalised TB patients had been in prison before ending up in hospital gives credence to the importance that the WHO ascribes to TB control in prisons (Bone,
Aerts, Grzemska, Kimerling, Kluge, Levy, Portaels, Raviglione \& Varaine, 2000): 16).

South Africa is doing its best to shake off the hackles of poverty. But, as regards real disposable income per household, citizens were equally poorly off at R9263 per annum in 2002 and at $R 8739$ in 1992. In 2002, Statistics South Africa established that the country's unemployment rate was $29.4 \%$ and for the Free State $33.5 \%$ (Dimant, 2003: 139). However, during the interviews only ten (18\%) Santoord Hospital patients stated that they had been unemployed before they fell ill with TB. On the other hand, anong the public ТB hospital patients, $15(43 \%)$ reported that they were unemployed before they contracted TB. Was there perhaps a tendency among Santoord patients to exaggerate their good fortune before they fell ill with TB? If so, this might then also have explained the higher mean monthly income reported by Santoord patients at R598 before they fell ill with TB, compared with the R478 of public TB hospital patients.

In the Free State the costs of T13 to patients include loss of income, as well as out-of-pocket expenses and time associated with undergoing TB treatment. These costs increase when patients default, require hospitalisation, and develop MDRTB (Meyer, Booysen \& De Graeve, 2003). In the current study more Santoord Hospital patients $(n=33 /$ $60 \%$ ) reported loss of monthly income due to their falling ill with TB and being hospitalised than did public hospital patients $(n=12 / 34 \%)$. On average, Santoord patients also reported having lost this income for a longer period ( 25 months) than did public hospital patients (15 months). These are protracted periods considering that a study in India found that the average period of loss of wages due to TB was three months (Rajeswari, Balasubramanian, Muniyandi, Geetharaman, Thresa \& Venkatesan, 1999: 869).

\section{Patients' health beliefs}

The interpretation of symptoms triggers the search for care and the kind of care that is sought. Rather than the symptoms themselves, it is the varying interpretation of their meaning and what they imply for a functioning social life that motivate people to seck care. Patients' understanding of symptoms, their choices on when and from whom to seek help, and their response to medical regimens conform to their own explanatory model of what is wrong with them. Nevertheless, health care providers often do not recognise this: "Patients'

Table 2: TB hospital patients' beliefs regarding how they fell ill with TB

\begin{tabular}{|l|l|l|}
\hline Response to open-ended question & SH & PH \\
\hline Uncertain, e.g. " really don't know". & $18(33.3)$ & $9(26.5)$ \\
\hline $\begin{array}{l}\text { Work and environmental factors, e.g. "dust", "chemicals", "air pollution" and } \\
\text { "working in the mines". }\end{array}$ & $15(27.8)$ & $5(14.7)$ \\
\hline $\begin{array}{l}\text { Western-medical, e.g. "from infected persons", "from somebody coughing", } \\
\text { "this is the result of AIDS" and "I had a weak immune system". }\end{array}$ & $13(24.8)$ & $14(41.2)$ \\
\hline Personal high-risk behaviour, e.g. "smoking", “alcohol" and "lack of hygiene". & $7(13.0)$ & $3(8.8)$ \\
\hline Diet, e.g. "poor food", "drinking too much cold liquids" and "coolaid". & $1(1.9)$ & $2(5.9)$ \\
\hline "Bewitchment". & - & $1(2.9)$ \\
\hline
\end{tabular}




\begin{tabular}{|l|l|c|c|c|c|c|}
\hline Statement & Hospital & Agree & Disagree & $\mathbf{X}^{2}$ & $\underline{\text { d }}$ & p \\
\hline \multirow{2}{*}{$\begin{array}{l}\text { "The medicine I am given at the hospital } \\
\text { will make me well." }\end{array}$} & $\mathrm{SH}$ & $45(83.3)$ & $9(16.7)$ & \multirow{2}{*}{11.6} & 1 & .001 \\
\cline { 2 - 5 } & $\mathrm{PH}$ & $15(48.4)$ & $16(51.6)$ & & & \\
\hline \multirow{2}{*}{$\begin{array}{l}\text { "Traditional medicines are more effective } \\
\text { than the medicine I receive from the } \\
\text { hospital." }\end{array}$} & $\mathrm{SH}$ & $8(15.7)$ & $43(84.3)$ & \multirow{2}{*}{9.0} & 1 & .003 \\
\cline { 2 - 5 } & $\mathrm{PH}$ & $12(48.0)$ & $13(52.0)$ & & & \\
\hline
\end{tabular}

Table 4: TB hospital patients' views of the necessity of their hospitalisation

\begin{tabular}{|c|c|c|c|c|c|c|}
\hline Statement & Hospital & Agree & Disagree & $x^{2}$ & $\underline{\text { df }}$ & p \\
\hline \multirow[t]{2}{*}{ "I am so ill that I need to be in hospital." } & SH & $33(60.0)$ & $22(40.0)$ & \multirow{2}{*}{6.0} & \multirow{2}{*}{1} & \multirow{2}{*}{.014} \\
\hline & $\mathrm{PH}$ & $28(84.8)$ & $5(15.2)$ & & & \\
\hline
\end{tabular}

efforts to cope with symptoms, or adapt treatment recommendations to the apparent course of the disease, such as lessening discomforting symptoms, are often construed by providers as ignorance, lack of concern, vacillation, or non-adherence" (Rubel \& Garro, 1992: 628).

Kelly (1999: 233) found that patients understood TB through the medical model. One-quarter $(n=13 / 25 \%)$ of the Santoord Hospital patients during the interviews offered a "western-medical" explanation in response to an openended question as to how they became ill with TB. A much larger proportion $(n=14 / 41 \%)$ of the public TB hospital patients offered such an explanation.

While Santoord Hospital patients more often did not know how they became ill with the disease, they were also more inclined to ascribe their infection with TB to work and environmental factors $(n=15 /$ $27 \%$ ) than were public TB hospital patients $(n=5 / 14 \%)$. These findings reflect negatively on the then current health education at both the concerned types of hospitals, but especially at Santoord where patients were hospitalised much longer than at public hospitals. In both samples large proportions of TB patients were uncertain about how they became ill with TB (Santoord Hospital, $n=18 / 33 \%$; public hospitals, $n=9 / 27 \%$ ). Given that the infectiousness of TB is such a prominent theme in TB health education, this situation was of grave concern.

As regards their beliefs in western vs. traditional medicine, Santoord patients were significantly more inclined to value the former. This might be explained by their comparatively longer experience of hospitalisation for $T B$ and their observation of the beneficial effects of the treatment provided on themselves and other patients.

Even though they were more inclined to value western medicine for TB, Santoord patients were also significantly more likely to disagree that it was necessary for them to be hospitalised than were public hospital patients.

\section{Patients' satisfaction with hospitalisation}

During the late 1990s many health facilities, and especially public hospitals, in South Africa were in a dilapidated state with crumbling electrical, water and steam systems. Accelerated decay of hospitals had resulted from minimal maintenance. The inappropriate design of many hospitals had led to overcrowding, lack of privacy and expensive modes of service delivery. Some hospitals had as many as $25 \%$ more beds in use than originally anticipated by the hospital planners and architects. This may be ascribed to the fact that the previous government had not upgraded or replaced hospitals as they reached the end of their natural lifespan (Doherty, Kraus \& Herbst, 1996: 65; Heunis, 2004c: 464-467).

The South African Demographic and
Health Survey of 1998 found, among a sample of 12860 households, that $12 \%$ of public hospital users were dissatisfied with the services rendered by these facilities, compared with $7 \%$ of private hospital users (Department of Health, 2002: 193). In 1998, rural hospitals in South Africa often had unreliable electricity $(33 \%)$ and water (39\%) supply. These hospitals often did not have e-mail access $(65 \%)$, functioning sonar equipment $(65 \%)$, oxygen in wards $(19 \%)$, monitoring of drug expenditure $(15 \%)$, community representation in the form of a hospital board $(40 \%)$, complaint procedures $(33 \%)$, after-hours X-ray services $(15 \%)$, and access to 24 -hour blood transfusion services $(44 \%)$ (Edwards-Miller, Pick, Conway, Fisher, Kgosidintsi, Kowo \& Weiner, 1998: 161 184).

In 1999, the nurse:patient ratio in South African public district hospitals was below that which was required, as was medical staffing levels in some cases (Morris, 2001: 180). It was anticipated that the Public Service Amendment Act No 5 of 1999 would allow hospital managers to appoint more and higher levels of staff. Nevertheless, the filling of vacant posts remained a key frustration. It was difficult to obtain approval for the filling of posts and to retain existing skilled staff in hospitals. South African hospitals were being depleted of their longest serving and most skilled nurses by voluntary severance packages and recruitment by overseas agencies (Boulle, Blecher \& 


\begin{tabular}{|c|c|c|c|c|c|c|}
\hline Statement & Hospital & Agree & Disagree & $\mathrm{X}^{2}$ & df & p \\
\hline \multirow{2}{*}{$\begin{array}{l}\text { "I am happy about the way I am treated } \\
\text { at this hospital." }\end{array}$} & SH & $34(63.0)$ & $20(37.0)$ & \multirow{2}{*}{7.0} & \multirow{2}{*}{1} & \multirow{2}{*}{.003} \\
\hline & $\mathrm{PH}$ & $32(91.4)$ & $3(8.6)$ & & & \\
\hline \multirow[t]{2}{*}{ "l am well looked after at this hospital." } & SH & $34(61.8)$ & $21(38.2)$ & \multirow{2}{*}{6.9} & \multirow{2}{*}{1} & \multirow{2}{*}{.009} \\
\hline & $\mathrm{PH}$ & $29(87.9)$ & $4(12.1)$ & & & \\
\hline
\end{tabular}

Burn, 2000: 231-238). Capital infrastructure and equipment were deteriorating at levels far exceeding expenditure on rehabilitation, maintenance and replacement of such infrastructure and equipment. Furthermore, real increases in funding for hospital services had, on aggregate, not translated into increased staffing, but were rather spent on increased salaries and benefits for existing staff.

Despite the aforementioned conditions at public hospitals - which must surely translate into high levels of discontent among public hospital users - it was found in the current study that TB patients at the NGO Santoord Hospital were significantly more dissatisfied with the care they received than were their public sector hospital counterparts.

Nápoles-Springer, Santoyo, Houston,
Pérez-Stable \& Stewart (2005) found that physicians' acceptance of the role of spirituality, of family and ethnicity-based discrimination were cultural factors specific to non-White patients, perceptions of the quality of their medical encounters. Radwin (2000: 179) found that perceptions of the quality of nursing care were characterised by professional knowledge, continuity, attentiveness, coordination, partnership, individualisation, rapport and caring. On their part Persson, Gustavsson, Hellström, Lappas \& Hultén (2005: 51) found that patients' perceptions of nursing care were strongly influenced by their dissatisfaction with the information they received about the results of medical examinations and laboratory tests. As regards the reasons for their dissatisfaction with care at Santoord Hospital, the following significant differences were observed between patients of this and the six public sector hospitals. Although substantial proportions of public hospital patients were also dissatisfied with all the aspects listed in Table 6, ranking according to the lambda test indicates that not receiving enough food and being unable to express their cultural beliefs were the most important sources of dissatisfaction characterising the NGO hospital patients as being more dissatisfied with care.

Only in two respects were most of the Santoord patients satisfied, safety at the hospital $(n=34 / 62 \%)$ and the provision of bedclothes $(n=31 / 56 \%)$. In contrast, most public TB hospital patients were satisfied, even very satisfied, with the general appearance of the hospital, safety, bathroom facilities, bedclothes, sleeping arrangements, privacy, hospital clothes and the distance the hospital was located from their homes.

\section{Table 6: TB patients' satisfaction with care: ranking of differences in Santoord Hospital and public hospitals}

\begin{tabular}{|c|c|c|c|c|c|c|c|}
\hline Statement & Hospital & Agree & Disagree & $X^{2}$ & $\underline{\text { fr }}$ & p & $\wedge$ \\
\hline $\begin{array}{l}\text { "I get enough food at this } \\
\text { hospital." }\end{array}$ & $\begin{array}{l}\text { SH } \\
\mathrm{PH}\end{array}$ & $\begin{array}{l}27(49.1) \\
25(71.4)\end{array}$ & $\begin{array}{l}28(50.9) \\
10(28.6)\end{array}$ & 4.4 & 1 & .036 & .893 \\
\hline $\begin{array}{l}\text { "l am able to express my culture } \\
\text { at this hospital." }\end{array}$ & $\begin{array}{l}\mathrm{SH} \\
\mathrm{PH}\end{array}$ & $\begin{array}{l}13(24.1) \\
15(53.6)\end{array}$ & $\begin{array}{l}41(75.9) \\
13(46.4)\end{array}$ & 7.1 & I & .008 & .705 \\
\hline $\begin{array}{l}\text { "I am satisfied with the general } \\
\text { appearance of this hospital." }\end{array}$ & $\begin{array}{l}\text { SH } \\
\text { PH }\end{array}$ & $\begin{array}{l}25(45.5) \\
28(80.0)\end{array}$ & $\begin{array}{l}30(54.5) \\
7(20.0)\end{array}$ & 10.5 & 1 & .001 & .499 \\
\hline $\begin{array}{l}\text { "I am satisfied with the distance } \\
\text { of this hospital from my home." }\end{array}$ & $\begin{array}{l}\text { SH } \\
\text { PH }\end{array}$ & $\begin{array}{l}13(23.6) \\
22(62.9)\end{array}$ & $\begin{array}{l}42(76.4) \\
13(37.1)\end{array}$ & 13.8 & 1 & .000 & .123 \\
\hline $\begin{array}{l}\text { "I have sufficient privacy at this } \\
\text { hospital." }\end{array}$ & $\begin{array}{l}\text { SH } \\
\text { PH }\end{array}$ & $\begin{array}{l}13(23.6) \\
21(65.6)\end{array}$ & $\begin{array}{l}42(76.4) \\
11(34.4)\end{array}$ & 15.0 & 1 & .000 & .072 \\
\hline
\end{tabular}




\begin{tabular}{|c|c|c|c|c|c|c|}
\hline Statement & Hospital & Agree & Disagree & $\mathbf{X}^{2}$ & df & p \\
\hline \multirow{2}{*}{$\begin{array}{l}\text { "I personally believe that having TB is a } \\
\text { disgrace." }\end{array}$} & SH & $26(47.3)$ & $29(52.7)$ & \multirow{2}{*}{15.7} & \multirow{2}{*}{1} & \multirow{2}{*}{.000} \\
\hline & $\mathrm{PH}$ & $31(88.6)$ & $4(11.4)$ & & & \\
\hline \multirow{2}{*}{$\begin{array}{l}\text { "Most people in my community believe } \\
\text { having TB is a disgrace." }\end{array}$} & $\mathrm{SH}$ & $29(54.7)$ & $24(45.3)$ & \multirow{2}{*}{6.6} & \multirow{2}{*}{1} & \multirow{2}{*}{.010} \\
\hline & $\mathrm{PH}$ & $27(81.8)$ & $6(18.2)$ & & & \\
\hline
\end{tabular}

Even though the public hospital patients recorded a higher degree of satisfaction in the survey, this should not be taken as unequivocal proof of amicable conditions at the public hospitals under study. Indeed, some authors extend Parsons's (1971: 285, 428 - 479) concept of the sick role to the hospitalised sick role, which apparently includes "an obligation to accept hospital routine without protest" (Cockerham 2004: 284). Short-term inpatient care subjects the patient to a role of submissiveness to authority, enforced co-operation, and depersonalised status: "heeft de zieke de plicht om de hulp van een arts aan te wenden en om met deze professionele instantie samen te werken teneinde de genezing the bevorderen. De rol van de zieke en van de arts komen zodoende met elkaar in contact en doen de sociale structuur ontstaan warbinnen de moderne medische praktijk functioneert" (Meulemans, 1999: 519). The current study suggests that protracted hospital stay may give rise to patients rejecting the submissiveness demanded by the traditional hospital sick role.

\section{Patients' experience of stigmatisation}

Having $\mathrm{TB}$ is an isolating experience (Kelly, 1999: 233). The survey showed that the majority of TB hospital patients in the combined sample experienced stigmatisation. Goffman (1963: 11) traced the Greek concept "stigma" to "bodily signs designed to expose something unusual and bad about the moral status of the signifier. The signs were cut or burnt into the body and advertised that the bearer was a slave, a criminal, or a traitor - a blemished person, ritually polluted, to be avoided, especially in public places". A human being has a stake in the forming of a situation through carrying into it symbolic meanings which will be to his/her advantage. During interaction these meanings are conveyed by verbal systems and body language intended to control others' definition of the situation. In hospitals patients are thwarted in this endeavour by the stigmas attached to them by others and which differentiate them from "normal" people.

Like Goffman, Foucault also devoted much attention to studying organisations in which individuals are physically separated from the outside world for long periods. In institutions such as Santoord Hospital people are kept hidden away or incarcerated. Such systems differ radically from other organisations because of their closed nature. Hence Foucault (1971: 229) remarks: "Is it surprising that prisons resemble factories, schools, barracks, hospitals, which all resemble prisons?" Fillingham (1993: 61) aptly captures Foucault's thoughts on stigmatisation in the hospital: "A bunch of people crowd around the bed staring at her, perhaps poking and feeling. She is supposed to be silent unless she is asked a question, and at times she is used as the basis for the ritual humiliation of a student. She becomes a thing, a disease, as the doctors are not interested in anything else about her."

In the current study it was found that public TB hospital patients were significantly more inclined to experience both self- and community-induced stigmatisation than Santoord Hospital patients. It could be, that where they were gathered together with many other TB patients for an extended period, Santoord patients had a broader frame of reference as to the extent of $\mathrm{TB}$, realised that there were many others in the same position as they, and therefore felt less different, less isolated and less stigmatised.

\section{Patients' adherence to treatment and absconding from hospital}

Patients' adherence to TB treatment is a major problem (Burman, Rietmeijer \& Sharbaro, 1997: 1168; Fouad Rabahi, Batista Rodrigues, Queiroz de Mello, de Almeida Netto \& Lineu Kritski, 2002: 63; Liefooghe, Michiels, Habib, Moran \& De Muynck, 1995: 1685; Meulemans, Mortelmans, Liefooghe, Mertens, Abkar Zaidi, Farooq Solangi \& De Muynck, 2002: 249). Instead of laying all blame for interrupted or discontinued treatment on the patient, it should be acknowledged that those people least likely to comply are those least able to comply (Hurtig, Porter \& Ogden, 1999: 553). Hence, in Ghana, Twumasi (1996:43) recommended that, instead of blaming TB patients for non-compliance with treatment, the TB programme ought to accept the responsibility of treatment failures: "A greater understanding of risk factors for non-compliance would facilitate formulation of policies to provide solutions to non-compliance. This would result in diminished TB morbidity and mortality, a reduced exposure to infective cases by the rest of the community and a reduction in the incidence of [TB] nationally." The perennial compliance problem lies at the heart of the persistent question of "individual agency" vs. "structural constraint": "How is a patient's 'compliance' to be understood: as individual action, as a response to social circumstances or cultural background, or as effect of structural factors and pressures, including access to treatment?" (Farmer \& Nardell, 1998: 1014). Compliance to TB treatment is a global conundrum.

Endeavours to retain more patients in treatment and the search for new combinations of medicine to ease discase control are both at the core of the biomedical institution. Not at the core of this institution is investigation of patients' preferred modes of treatment and of their understanding of the disease and how this encourages or discourages 
the seeking of biomedical care. This is probably because delivery of health care is governed by time-honoured traditions learned during professional training and supported by programmatic norms. Thus, efforts to modify attitudes and behaviour of clinical staff members often meet with resistance. To illustrate this problem, Rubel \& Garro (1992: 631 - 632) discuss research at San Francisco General Hospital where in 1996 more than a quarter of TB patients were not meeting their treatment appointments. The researchers' approach was firstly to interview hospital staff to ascertain their assessment of the problem. The staff attributed irregular attendance to the social and cultural characteristics of the user population: "elderly patients, workers, skid row alcoholics, the uneducated or ignorant, and those with a language barrier such as the Chinese and Latin Americans". The health workers claimed that such patients failed to attend treatment as regularly as other groups. The study, secondly, also included a patient interview survey. The patients advanced altogether different reasons for missed appointments, e.g. inconvenient clinic open hours and location; registration repeated at each visit; rigidity in taking patients in order of registration regardless of extenuating circumstances, overcrowding and poor ventilation in the clinic, punitive staff practices, and doctors not being able to converse with patients in their own language. The largely contradictory results of the two surveys led to decisions to reorganise services, decentralise staff into district teams, and to make them available in the neighbourhoods where patients lived and at times suiting patients' work schedules. In-service education took place to inform staff of patients' points of view and the implications thereof. These interventions - based on consideration of patients' social lives and cultural expectations decreased missed appointments for TB treatment from $26 \%$ to $4 \%$.

Historical factors impacting on TB treatment adherence in South Africa include that the country lacked adequate health facilities or staff to supervise treatment. The responsibility to achieve "treatment-to-cure" was left to patients themselves. Patients were traditionally labelled as "defaulters", implying that they were to blame. Moreover, in the past white medical authorities in South A frica often attributed treatment failure to blacks' "ignorance or native mentality" (Packard, 1992: 50-54). Some of the factors contributing to non-completion of treatment in South A frica were common to outpatient $\mathrm{TB}$ treatment programmes around the world. However, others were peculiar to the discriminatory political and economic realities of a country in which apartheid ruled, e.g. most blacks who contracted TB lost their jobs.

The emergence of MDRTB, and its associated compliance issues, has been described as "thorny from the perspective of a host of socio-medical disciplines" (Farmer, 1997: 349): The word "compliant" itself, "has the unfortunate connotation that the patient is docile and subservient to the provider". Farmer finds it even more unfortunate that the term exaggerates "patient agency", since it implies that all patients possess the ability to comply or not to comply with chemotherapy: This makes no sense since "[e]xperience across the boundaries of time and place have shown that there are radical differences in the ability of different populations to comply with demanding therapies".

Poor application of patient-centred care has jeopardised adherence to TB treatment in the Free State (Van Rensburg et al 2004: 1128). How might the adherence of TB patients to their treatment in hospitals be described? During the interviews, Santoord and public hospital patients were asked if they had ever forgotten to take their medication. In the combined sample only two $(4 \%)$ answered that they had. They were both in the Santoord Hospital group. When asked what the reason for this omission had been, one stated that he was asleep when the nurse brought the medicine, while the other "just forgot". Patients were also asked outright: "Have you ever purposely refrained from taking you medication?" Again, only two respondents admitted that they had. Both these Santoord Hospital patients cited the side effects of the TB treatment as the reason for their behaviour.

During the interviews patients were also asked if they had ever left any hospital, where they were undergoing $\mathrm{TB}$ treatment, without being officially discharged or granted leave of absence by the hospital. Of the 18 Santoord Hospital patients who had previously been hospitalised for TB, five answered that they had, as opposed to none of the public hospital patients. All of the "absconders" among the Santoord patients reported that they were back in hospital within five months. In fact, one was back within one week and another within one month. Two of the patients stated that they had found ways to continue taking their TB treatment while absconding. Respectively, the five patients who had absconded provided the following reasons for absconding: "The person looking after my house had damaged it", "I needed to see my children", "I thought I was cured", "It was my father's funeral" and, "I did not get enough food at the hospital".

When asked how their health was affected by their absconding from hospital, four of the patients stated that their health had deteriorated. Ironically, the other stated that her health had improved. She claimed that she had completed her treatment at a clinic. The five absconders were also asked what they did while away from the hospital. Two stated that they sought employment. one went back to work, and another attended a funeral. The other stated that he did "nothing". What made these patients return to hospital? Judging from their responses they had little choice in the matter: "I became very ill" $(n=2)$; "The 'tleleniki' [clinic] ordered it" $(n=1)$; "My employer sent me back" ( $n=1)$, and "My father forced me to return" $(n=1)$.

The survey also set out to establish how absconding patients were received back at hospital. Three of the five patients stated that they were "welcomed". One said that the hospital staff were angry with him and even refused to treat him for a while. The other was reportedly told by a Santoord staff member to "keep quiet" about having absconded.

\section{Conclusion}

A cynical interpretation of the findings of the survey would be to infer that the public hospital TB patients were more satisfied with care because they had not endured a long enough episode of it. Indeed, it is a limitation of the study that the stances of (long-term) Santoord Hospital patients are compared with those of (short-term) public hospital patients. However, barring private-sector hospital care, at the time of the survey these were the only hospitalisation options available to those reliant on public and state-aided 
health care.

By 2003 the Free State was not the only province that no longer had a SANTA hospital. North West, Limpopo, and the Northern Cape had also done away with this type of NGO hospital care. Was poor quality of care a contributing factor in the demise of SANTA hospitals? The patient survey at Santoord Hospital indeed suggests that this was the case. It was not that Santoord patients did not want to be hospitalised. Rather they just did not want to be hospitalised at Santoord. Here they were mostly dissatisfied with being far from home, having little privacy and limited opportunity to either express their culture or to engage in recreation during long months of "incarceration". While Santoord patients appreciated the availability of the drugs they required and the fact that their health improved, they also strongly protested against the poor health care that they experienced at this hospital.

While cautioning to "isolate such beds from others", a previous paper of the Joint Free State TB Research Project recommended that public district hospitals should reserve beds for TB cases (Heunis 2005: 251). The current study's research question, How appropriate was the closing of a hospital that contrihuted to $T B$ control for half a century?, and its attempt to answer this from the patient's perspective, begets the same answer - rather public district hospitals than Santoord Hospital.

\section{Acknowledgements}

Sincere gratitude is acknowledged to the following institutions for generous support of the Joint research project on tuberculosis control in the Free State: from infection to cure: On the Belgian side, the Science, Innovation and Media Department of the Ministry of the Flemish Community; the Prince Leopold Institute of Tropical Medicine; and the University of Antwerp. On the South African side, the former South African Department of ARTS, Culture, Science and Technology; the Medical Research Council of South Africa; the National Research Foundation of South Africa; and the Anglo American Chairman's Fund. We are also grateful to Dr. Z. Matebesi, Mr. I. Itumeleng and Me. D. Molehe for conducting the interviews. Finally, we are indebted to the Free State Department of Health and the South African National
Tuberculosis Association (SANTA) for authorising and supporting the research and for entertaining the findings.

\section{References}

AI.TENROXEL, L 2001: TB fighters face crisis over spending scandals. The Star, 26 March 2001: 6.

BONE, A; AERTS, A; GRZEMSKA, M; KIMIRLING, M; KLUGE,H; LEVY, M; PORTAELS, F; RAVIGLIONE, M \& VARAINE, F 2000: Tuberculosis control in prisons: A Manual for programme managers. Geneva: WHO.

BOULLE, A; BLECHER, M \& BURN, A 2000: Hospital restructuring. (In: Health Systems Trust Ed. 2000: South African Health Review, 2000. Durban: Health Systems Trust: pp 231 - 250).

BURMAN, WJ; RIETMEIJER, CA \& SHARBARO, JA 1997: Noncompliance with directly observed therapy for tuberculosis. Chest, $111(5)$ : $1168-1173$.

COCKERHAM, WC 2004: Medical sociology. Upper Saddle River: Pearson Prentice Hall.

DEPARTMENT OF HEALTH 2002: South African Demographic and Health Survey, 1998. Pretoria: Government Publishers.

DIMANT, T 2003: Business and employment. (In: Kane-Berman, J; Henderson, J \& Morton, L Eds. 2003: South Africa Survey, 2002/2003. Johannesburg: South African Institute of Race Relations, pp 139 -223).

DOHERTY, J; KRAUS, R \& HERBST, $K$ 1996: Health facilities. South African Health Review, 1996. (In: Health Systems Trust Ed. 1998: South African Health Review, 1998. Durban: Health Systems Trust, pp 65-72).

EDWARIDS-MILLER, J; PICK, W; CONWAY, S; FISHER, B; KGOSIDINTSI, N; KOWO, H \& WEINER, R 1998: Measuring quality of care in South African clinics and hospitals. (In: Health Systems Trust Ed. 1998: South African Health Review, 1998. Durban: Health Systems Trust, pp 157 192).

FARMER, P 1997: Social scientists and the new tuberculosis. Social Science \& Medicine, 44: 347 - 358.
FARMER, P \& NARDELL, E 1998: Nihilism and pragmatism in tuberculosis control. American Journal of Public Health, 88(7): 1014.

FILLINGHAM, LA 1993: Foucault for beginners. London: Writers and Readers.

FOUAD RABAHI, M; BATISTA RODRIGUES,A;QUEIROZDEMELLO, F; CAETANODE ALMEIDA NETTO,F \& LINEU KRITSKI, A, 2002: Noncompliance with tuberculosis treatment by patients at a tuberculosis and AIDS reference hospital in Midwestern Brazil. Brazilian Joumal of Infectious Diseases, 6(2): 63-73.

FOUCAULT, M 1971: Madness and civilization: $A$ history of insanity in the age of reason. New York: Pantheon Books.

GOFFMAN, E 1963: Stigma: Notes on the management of spoiled identity. Englewood Cliffs: Penguin Books.

HEUNIS, JC 2002a: The hospitalisation of TB patients in the Free State: preliminary findings of a hospital patient survey, October-November 2000. (Tuberculosis Strategic Planning Session for DC 17 organised by the Department of Health: 22 January: Pelonomi Hospital: Bloemfontein).

HEUNIS, JC 2002b: Hospitalisation for tuberculosis in the Free State: focus on the patient experience. (Joint TB Research Project Feedback Workshops organised by the Centre for Health Systems Research \& Development: 2230 May: Department of Health: Sasolburg, Bethlehem, Welkom, Harrismith, Bloemfontein and Trompsburg).

HEUNIS, JC 2002c: Hospitalisation of tuberculosis patients. (Seminar organised by the Department of Community Health: 2 August: University of the Free State: Bloemfontein).

HEUNIS, JC 2002d: Hospitalisation for tuberculosis: reflections on policy, poverty and the patient. (Seminar on Tuberculosis in the Free State organised by the University of Antwerp: 3 August: Antwerp, Belgium)

HEUNIS, JC 2002e: Tuberculosis control at Free State hospitals: policy and 
practice. (Biennial International Congress on Health and Society in Europe organised by the European Society for Health and Medical Sociology: 28-31 August: Groningen, The Netherlands).

HEUNIS, JC 2002f: Hospitalisation for tuberculosis in the Free State, South Africa: health systems policy and practice and the patient experience. (Third European Congress on Tropical Medicine and International Health organised by the Federation of the European Societies of Tropical Medicine and International Healıh (FESTMIH): 811 September: Lisbon, Portugal).

HEUNIS, JC 2003: The role of the public district hospital in TB control. (Conference organised by the Centre for Health Systems Research \& Development: 11-12 November: 2003: University of the Free State: Bloemfontein).

HEUNIS, JC 2004a: Hospitalisation for TB: the emerging role of the public district hospital in the Free State. (World TB Day Commemorative Workshop organised by the Prince Leopold Institute of Tropical Medicine: 5 March 2004: Antwerp, Belgium).

HEUNIS, JC 2004b: Hospitalisation for tuberculosis in the Free State, South Africa. Bloemfontein: University of the Free State. (PhD Thesis).

HEUNIS, JC 2004c: Hospitals and hospital reform in South Africa. (In: Van Rensburg, HCJ Ed. 2004: Health and health care in South Africa. Pretoria: Van Schaik Publishers, pp 459 - 505).

HEUNIS, JC 2005: Hospitalisation for TB in the Free State: opinions of health workers and managers. Acta Academica Supplementum. 2005( 1): 221 - 253.

HEUNIS, JC \& JANSE VAN RENSBURG-BONTHUYZEN, E 2002: Preliminary findings of the Joint Free State Tuberculosis Research Project. (Medium Term Development Plan Meeting organised by the Free State Department of Health: 18 February 2002: Bloemfontein).

HURTIG, AK; PORTER, JDH \& OGDEN, JA 1999: Tuberculosis control and directly observed therapy from the public health/human rights perspective.
The International Journal of Tuberculosis and Lung Disease. 3(7): 553 - 560.

INPATIENT CARE TEAM 2003: Interviews on 31 October 2003 with two representatives from the National Department of Health's Inpatient Care Team regarding SANTA and Lifecare hospitals.

JANSE VAN RENSBURGBONTHUYZEN, E 2005: Staff capacity and resources at nine Free State clinics: shortcomings in the TB programme. Acta Academica Supplementum. 2005(1): 192 -220 .

KELLY,P 1999: Isolation and stigma: the experience of patients with active tuberculosis Journal of Community Health Nursing. 16(4): $233-241$.

KIMERIING, ME 2000: The Russian equation: An evolving paradigm in tuberculosis control. The International Journal of Tuberculosis and Lung Disease, 4(12): S160 - S170.

KIRK, P 2001: Santa head office faces closure. Mail \& Guardian. 23 March 2001: 3.

I IEFOOXFHE, R; MICHIELS, N; HABIB, S; MORAN, MB \& DE MUYNCK, A 1995: Perception and social consequences of tuberculosis: A focus group study of tuberculosis patients in Sialkot, Pakistan. Social Science \& Medicine. 41(12): $1685-1692$.

MATEBESI, SZ; MEULEMANS, H \& TIMMERMAN, C 2005: Healthcareseeking behaviour among clinic-based tuberculosis patients. Acta Academica Supplementum. 2005( 1): 154 - 172

MEULEMANS, H 1999: Gezondheid, recht en afwijken gedrag. (In : Van Loon, F\& Van Acken, K Eds. 1999: 60 maal recht en 1 maal wyn. Leuven: Acco, pp 519 527).

MEULEMANS, H; MORTEL MANS, D; LIEFOOGHF, R; MERIENS, P;ABKAR ZAIDI, S; FAROOQ SOLANGI, M \& DE MUYNCK, A 2002: The limits to patient compliance with directly observed therapy for tuberculosis: A socio-medical study in Pakistan. International Journal of Health Planning and Management. 17: 249 - 267.

MEYER, K; BOOYSEN, F \& DE
GRAEVE, D 2003: An economic analysis of TB in the Free State. (Conference organised by the Centre for Health Systems Research \& Development: 11-12 November 2003: University of the Free State: Bloemfontein).

MORRIS, G 2001: Improving quality of services. (In: Health Systems Trust Ed. 2001: South African Health Review, 2001 Durban: Health Systems Trust, pp 175 186).

NÁPOLES-SPRINGER, AM; SANTOYO,J; HOUSTON, K; PÉREZSTABLE, EJ \& STEWART, AL 2005: Patients' perceptions of cultural factors affecting the quality of their medical encounters. Health Expectations. 8: 4 17.

NEUMAN, WI, 2000: Social research methods: qualitative and quantitative approaches. Boston: Allyn and Bacon.

PACKARD, RM 1992: Industrialization, rural poverty, and tuberculosis in South Africa, 1850-1950. (nㅡ: Feierman, S \& Janzen, JM Eds. 1992: The social basis of health and healing in Africa. Berkeley: University of California Press, pp 43 - 105)

PARSONS, T 1951: The social system. Glencoe: The Free Press.

PERSSON, E; GUSTAVSSON, B; HELISTRÖM, A; LAPPAS, G \& HULTÉN, I, 2005: Ostomy patients' perceptions of quality of care. Journal of Advanced Nursing. 49(1): $51-58$.

PORTAELS, F 2003: New challenges in the global control of MDRTB. (Conference organised by the Centre for Health Systems Research \& Development: 11-12 November 2003: University of the Free State: Bloemfontein).

RADWIN L 2000: Oncology patients' perceptions of quality nursing care. Research in Nursing \& Health. 23(605): $179-190$.

RAJESWA RI, $\quad$ R; BAI.ASUBRAMANIAN, $M$; MUNIYANDI, M; GEETHARAMAN,S; THRFSA, $X$ \& VENKATESAN, $P$ 1999: Socio-economic impact of tuberculosis on patients and family in India. The International Joumal of Tuberculosis and Lung Disease, 3(10): 869 - 877. 
REICHMAX, LB \& HOPKINS TANNE, J 2002: Time bomb: The global epidemic of multi-drug-resistant tuberculosis. New York: McGraw-Hill.

RUBEL, AJ \& GARRO, LC 1992: Social and cultural factors in the successful control of Tuberculosis. Public Health Reports, 107:626-636.

SCHLUGER, N; CIOTOLI,C;COHEN, D; JOHNSON, H \& ROM, WN 1995: Comprehensive tuberculosis control for patients at high risk for noncompliance. American Journal of Respiratory and Critical Care Medicine, 151: 1486 - 1490.

SCHNEIDER, H. \& PALMER, N 2002: Getting to the truth? Researching user views of primary health care. Health Policy and Planning, 17(1): $32-41$.

SINGLETON,L; TURNER,M;HASKAL, R; ETKIND, S; TRICARICO, M \& NARDELL, E 1997: Long-term hospitalization for tuberculosis control: Experience with a medical-psychosocial inpatient unit. Journal of the American Medical Association, 278(10): 838 - 842 .

TURNER, B 2002: The statesman's yearbook: The politics, cultures and economies of the world. Hampshire: Palgrave Macmillan.

TWUMASI, P.A 1996: Non-compliance with tuberculosis treatment: The Kumasi experience. Tropical Doctor, January: 43.

VAN RENSBURG, J 2000: The secretariat scene: crisis. TB and health news: SANTA, 39(7): 2.

VAN RENSBURG, HCJ; MEULEMANS, H; RIGOUTS, L; HEUNIS, JC; JANSE VAN RENSBURG, E; MATEBESI, SZ; VAN DERSPOEL, A; TIMMERMAN, C; DE GRAEVE, D; PAUWELS, L; PORTAELS, F; GRYSEELS, B \& VAN HOUTTE, J 2004: Social research as an intervention tool in tuberculosis control. The International Journal of Tuberculosis and Lung Disease, 8(9): 1127 - 1129.

VANRENSBURG,HCJ; MEULEMANS, H \& RIGOUTS, L, 2005: Tuberculosis: the complexity of the phenomenon and the magnitude of the problem. Acta Academica Supplementum, 2005(1): i - xv.

VAN VUUREN, RDJ 2001: Interview on II November 2001 with Centre Supervisor regarding Santoord 